\title{
Jerry Fodor and the Reinterpretation of the Phrenological Model
}

\author{
Cleverson Leite Bastos ${ }^{1, *}$, Gustavo Luiz Gava ${ }^{2}$, Carlos Eduardo de Carvalho Vargas ${ }^{3}$ \\ ${ }^{1}$ PPGF, Pontifical Catholic University of Paraná, Curitiba, Brazil \\ ${ }^{2}$ Core Human Formation, Positivo Online University, Curitiba, Brazil \\ ${ }^{3}$ Pontifical Catholic University of Paraná, Curitiba, Brazil \\ *Corresponding author: leite.bastos@pucpr.br
}

Received September 12, 2014; Revised December 02, 2014; Accepted December 14, 2014

\begin{abstract}
In tentative to support the "vertical tradition" in faculty psychology, Jerry Fodor reached resources in the phrenological model of Franz Gall. Fodor offers a reinterpretation of Gall's work to demonstrate the emphasis investigative in the study of the mental structures and, indirectly, in the actual memory research, judgment, attention, among others. Jerry Fodor sought to highlight affirmative evidence that hides the phrenology of Gall, correcting and improving the phrenological model to research functional subsystems in the human mind. Deeping this issue, it is understood that the issue of modularity of mind contributed to undertake the current studies on the processes of teaching and learning, departing from the modular model proposed by Gall and Fodor.
\end{abstract}

Keywords: Jerry Fodor, Franz Joseph Gall, modularity of mind, cognitive neuroscience, philosophy of education

Cite This Article: Cleverson Leite Bastos, Gustavo Luiz Gava, and Carlos Eduardo de Carvalho Vargas, "Jerry Fodor and the Reinterpretation of the Phrenological Model." American Journal of Educational Research, vol. 2, no. 12C (2014): 8-10. doi: 10.12691/education-2-12C-3.

\section{Introduction}

In the awakening of the nineteenth century, the study of sensory physiology excelled in advancement of knowledge about the nature of the brain and its anatomical subdivisions. The scientists wanted to discover the characteristics of the cortex, the connections between the right and left hemispheres; i.e., the psychological and physiological attributes stood out in the polls neuroanatomy able to determine the personality traits of human beings.

By the nineteenth century, researchers led by Franz Joseph Gall and Joseph G. Spurzheim (between 1810 and 1819), held that the brain was organized with 35 specific functions. "the doctrine of phrenology, as propounded by Gall, states that every psychological function or faculty is dependent upon specific region of brain and if the particular function is well developed in person, the concerned region in the brain will expand and push out the brain and hence, a part of the skull" (Singh, 1991, p. 69).

In this study of the brain, we highlight such phrenologists that were the first scholars to theorize the possible location of human faculties in the human brain. They was searching the precise identification of the corresponding functional brain area (Goodwin, 2005, pp. 88- 89). The scientific effort initiated by the study of brain function was soon repulsed as a pseudo-scientism unfounded. It is evident that many psychology texts extalt (only) that obliquity proto-scientific following only scholars who argued opposing views. Such a position - as
Fodor points out -, was obtuse and condemned the origins of the phrenological movement, reducing it to a misunderstanding, even known as "mad science", which showed an objectionable positioning, since phrenology had valuable points contribution to the study of brain functions. We want to emphasize that phrenology, later, came to favor new theories about the psychological faculties and multiple intelligences. We believe that the Fodor' studies can contribute directly and indirectly to the pedagogical researches, helping to explain the cognitive processes involved in teaching and learning.

Unlike chimeric pseudoscientific conjecture, the origins of phrenology, in the work of Franz Joseph Gall, demonstrates that besides an anatomist and successful medical care, the theory of "cranioscopy" (examination of the skull for diagnostic purposes) is historically significant in studies of location of brain function. Such mistakes, however, could not act as obstacles that condemn the basis of such research, responsible for creating the first theories about the location of mental structures.

According to Gardner (1994, p. 10), phrenology had scoped to investigate the variations, such as size and shape of human skulls. And from there, the phrenology examines some specific characteristics that could identify the characteristics of each individual. The specialist trained in phrenological reading would be able to find the points that could describe the specifics of each psychological profile, in search for "mental organs" and its varieties cataloged by Franz Joseph Gall and Joseph Spurzheim.

Franz J. Gall came to develop a kind of brain mapping corresponding to various mental faculties, each one with 
its own cranial identification; as the impulse to steal, which could be identified through an accurate survey, measured at the corresponding location of the skull of each individual. We can even observer that studies on the brain functions are part of the current educational psychology. If we make this historic research, we can consider the Gall's teaching in many issues. Just as Howard Gardner (1994), Jerry Fodor also made this rescue on the Gall's project, so that other researches could check the same importance.

\section{The Setback of Phrenology}

The setback of Gall's phrenology was consummated from the moment in that the scientific community relegated it to the position of pseudoscience, precisely because of the impossibility of precision and theoretical refutation. However, as previously mentioned, many scholars emphasize, currently, the importance of phrenology of Gall from a more sophisticated crossepistemological interpretation.

To neuroscientist Nicole Fiori (2008, p. 17) said that Gall had the primacy in the theory that locates the brain functions (phrenology). Gardner (1994, p. 10) added that is "fallacious" disregard Gall and the phrenology entirely. According to Fiori (2006, p. 17), many critics of Gall were wrong when they said that all brain regions could exercise all the functions.

Even contemporaneously, we must recognize the historical importance of phrenology, insofar as Gall presented a concept of the brain as a whole (Fiori, 2006, p. 17), corroborating some functional notions. According to neuroscientist Sabbatini (1997, p. 1), Gall was right from this analysis. However, Gall was completely misguided in explain how the brain could do this when he used the model of the creation of topological maps. For Sabbatini (1997, p. 1), the Gall's localizationist theory was pretty influential at the time and marked several questions on the subject as well as his assertiveness in conceiving the brain as an organ of mind.

Gall did not share the idea that there are general faculties, perceptual and mnemonic, among other activities of horizontal character. This would be a fiction, according to the researcher (Fodor, 1983, p. 14). Therefore, it is understood that, in Gall's theory, the psychological functions could, in addition to localized function, act as independent operating units. This premise served exactly to the vision of the modularity of mind in Jerry Fodor1s theory. As Gall, Fodor believes that mental processes are thought more consistently when understood as cognitive closure (Gardner, 1994, p. 217). Further, we add that Fodor protests against the idea of a horizontal processing, preferring to discuss vertical modules as a characteristic mode of operation (Candiotto, 2008).

\subsection{Jerry Fodor's Research on the Vertical Model}

For Fodor (1983, pp. 14-15), the main difference in the Gall's model and his theory of vertical modules is that his new theory does not maintains the Gall's distinctions between skill and inclination. According to Fodor, this fine distinction may have led Gall to investigate mistakenly the functioning of vertical faculties. In the conceptions formulated by Gall, he also does not make a distinction between cognition and volition; i.e., a particular individual, even wanting to play a musical instrument, could not possess the ability to execute this desire. However, the core of the Gall's theory, for Fodor, is that the psychological mechanisms - cognitive domains - have specificities (abilities) that differ.

The theory under discussion presents the results obtained in the study of the evolution of the mind into three architectural phases proposed by Steven Mithen (2002), especially to highlight cognitive archaeological approach. In Mithen' study, in addition to evidence of considerable prominence in changes of the skull, there is also a effort of vertical modules. Mithen (2002, p. 105) believes that the modular vertical integration occurred in the second phase of the evolution of the mind. During this period, various intelligences formed in specialized fields. This model goes to meets the anatomical prerogatives of Gall and the epistemological reflections of Fodor.

According to Jerry Fodor (1983, p 15), there is a difference that becomes clear in the phrenological theory of Gall; i.e., the vertical psychological mechanisms differ mainly with respect to the unique cognitive ability, when functionally compared to others abilities (music vs. math): "there are as many different classes as differentiated qualities of intellect" (Gall apud Fodor, 1983, p. 15).

However, the intellect itself could not be regarded as a special faculty - horizontal - because it lacks a center itself. In this case, for Gall, perception, memory and judgment would be only common attributes of their own psychological qualities: "you have to discover the fundamental skills of the mind, because only they have independent bodies in the brain" (Gall apud Fodor, 1983, p. 16). For Fodor, such conceptions of Gall infer a neural specificity - vertical faculties - that could receive, genetically, a proper name. According to Fodor, this theory is in consonance with the innatist proposal.

Fodor's views about the phrenological model assumes that Gall distinguished faculties that could differ from one person to another, i.e., these concepts indicated that psychological and neural mechanisms are different when it comes to different vertical faculties. For Fodor (1983, pp. 19-20), these individual differences stand out as one of the most striking features of his work, and, at the same time, are placed as a contradiction between the notion of faculties and instincts, as, for example, the ability in soccer is not genetically determined on a neurological basis. The instinct would be genetically determined and not the vertical college, inasmuch as that this is form of conduct between species. Vertical faculties - opposite of Gall - are constructed from relatively specialized skills of each individual.

\section{The Modularity of Gall and the Equipotential Evolution}

From Gallian model of vertical faculties specifically located, Fodor emphasizes that these aspects contributed to the equipotential tradition - organizing neural structures, including, sequentially, Wernicke and Broca. In fact, in the last century, the discoveries and theories of Gall, 
Broca and Wernicke brought considerable questions to philosophical, psychological and medical theories.

It was during the 1920s that the search for the location of intelligence (function) suffered more significant changes, mainly through the so-called equipotential view, designed by neuropsychologist Karl Spencer Lashley (1951). In their research, he initiated demonstrating that the function was extremely complex and could not be located in the brain, because many cortical areas not related to the control of certain functions (Goowin, 2005, p. 106). Lashley's research, relating brain to behavior, was culminating in the formulation of new theories.

The equipotential view defended by Lashley attempted to demonstrate that the brain, as a whole, was responsible for the behavior of a particular functional area, which could be correlated with each other, showing a certain behavior. The processed information - such as learning, for example - could be represented throughout the brain. At this point, the Lashley's theory is close to the statements that Fodor called horizontal faculty, i.e., a cognitive explanation of the unmodulated nervous system. Lashley was important to prepare the ground for a scientific-cognitive approach to the understanding of the behavior and the thought (Gardner, 1996, p. 279). After the dissemination of Lashley's research, in opposition to the localizacionists, increased the philosophical movement of holistics.

For holistics, human behavior can not be explained based on neural determinations, since it provides a strong synergy with the overall view advocated by Gestalt psychologists. However, many critics argue that the position defend by Lashley is quite strong. It appears that the controversy settles between localizationism and equipotencialism proceeds from the Gallian period.

\section{Conclusions}

For Jerry Fodor (1983), the model of vertical faculties of specific domain, genetically determined, is presented through a functional mental structure. Its operation occurs at the center of autonomous and specific cognitive domains. The rescue of the Gall's view establishes a fusion between innateness and specificity of cognitive abilities. We can see that the Gallian antecedent served as support to the notion of cognitive module (Candiotto, 2008 , p. 126), widely used in current pedagogical schools and their teaching and learning theories.

However, Fodor found that there was a possibility to contemplate the existence of non-modular processes, supported by a horizontal power. From this absence of specific domain we could conceive cognitive characteristics of thought itself, fixing beliefs, etc. Fodor was thinking a kind of non-local functional architecture, able to extend modular domains. However, Fodor believes that the assumptions, on which the horizontal processes are supported, don't have more solid credit to act as a compelling argument for the understanding of cognitivists. There is his pessimism regarding the theories that supports the horizontal faculties (Fodor, 1983, p. 38).

Jerry Fodor (1983, pp. 37-38) believes that the best way to make the cognitive systems more palatable would accept its modularity, supported by vertical faculties, endowed with an informational encapsulation. However, regarding cognitive actions, Fodor - distancing himself from the idea of horizontal faculty - conceives the theory of central processor. He thinks that the modules have a cognitive informational link through this general processor.

We think we can help to decrease the intellectual distance between the cognitive neuroscience and the philosophy of education (Morgan, 2003). In terms of applications in the philosophy of education, neuroscientific achievements can be related to other methodological processes, such as phenomenology, for example (Ratcliffe, 2010). However, thinking specifically in the philosophy of Jerry Fodor (1983), we should seek, in the research on teaching and learning, which faculties are modular and psychological, and which intelligences - not modular would really horizontal. Perhaps there is, the way to understand the current difficulties of some students with cognitive diversity.

\section{References}

[1] Candiotto, K. Fundamentos epistemológicos da teoria modular da mente de Jerry A. Fodor. Trans/Form/Ação, Marília, v. 31, n. 2, pp. 119-135, 2008.

[2] Fiori, N. As neurociências cognitivas. Vozes, Petrópolis, 2008.

[3] Fodor, J. The Modularity of Mind. Massachusetts, Cambridge, The MIT Press, 1983.

[4] Gardner, H. Estruturas da mente: a teoria das inteligências múltiplas. Edusp, São Paulo, 1996.

[5] Goodwin, J. História da psicologia moderna. Cultrix, São Paulo, 2005.

[6] Lashley, K. The problem of serial order in behavior. In: Jeffress, L. (ed.). Cerebral Mechanisms in Behavior, pp. 506-528. New York: Wiley, 1951.

[7] Mithen, S. A pré-história da mente: uma busca das origens da arte, da religião e da ciência. Unesp, São Paulo, 2002.

[8] Morgan, H. Real Learning: A Bridge to Cognitive Neuroscience. Lanham: Scarecrown Education: R \& L Education, 2003.

[9] Sabbatini, R. O mapa frenológico. Campinas: Unicamp, 1997. Acessado em 09 julho, 2014, de http://cerebromente.org.br/n01/frenolog/frenologia_port.htm. [Accessed Nov. 25, 2014].

[10] Ratcliffe, M. The Phenomenology and Neurobiology of Moods and Emotions. In: Gallagher, S.; Schmicking, D. Handbook of Phenomenology and Cognitive Science. Dordrecht: Springer, 2010, p. 123-140.

[11] Singh, A. K. The Comprehensive History of Psychology. Delhi: Motilal Banarsidass, 1991. 